\title{
An Ecological Study of the Role of Obesity and Excessive Alcohol Consumption on the Risk for Epithelioid Hemangioendothelioma Cancer of the Liver, Lungs, and Bones
}

\author{
Brina M. Hollis* \\ School of Health Sciences, Kaplan University, Florida, USA \\ *Corresponding author: brina.hollis@gmail.com
}

Received July 29, 2014; Revised August 15, 2014; Accepted August 24, 2014

\begin{abstract}
Purpose: To examine excessive alcohol consumption and obesity as risk factors for epithelioid hemangioendothelioma (EHE) of the liver, lungs, and bones. Methods: The nine tenets of the Bradford Hill criteria of epidemiological causation served as the conceptual framework of this study. Documented cases of EHE of the liver, lungs, and bones were collected from the International Hemangioendothelioma Epithelioid and Related Vascular Disorders registry database. A secondary data analysis was conducted using the Behavioral Risk Factor Surveillance System telephone survey. US census data were employed to obtain regional demographic data that were used as covariate controls for the study. Correlation and regression analyses were conducted to examine relationships among the rates of regional obesity, alcohol consumption, and prevalence of EHE of the liver, lungs, and bones. Results: Obesity proved to be a significant predictor of EHE of the liver, lungs, and bones; excessive alcohol consumption was not a significant predictor. Income was found to be a statistically significant covariate. Conclusions: The results highlight the need for research further examining the link between obesity and EHE. Knowledge of potential risk factors may facilitate greater understanding of this rare cancer and the development of improved protocols to expand EHE screening and documentation.
\end{abstract}

Keywords: epithelioid hemangioendothelioma, obesity, alcohol consumption

Cite This Article: Brina M. Hollis, "An Ecological Study of the Role of Obesity and Excessive Alcohol Consumption on the Risk for Epithelioid Hemangioendothelioma Cancer of the Liver, Lungs, and Bones." American Journal of Public Health Research, vol. 2, no. 4 (2014): 170-175. doi: 10.12691/ajphr-2-4-7.

\section{Introduction}

Epithelioid hemangioendothelioma (EHE) was first defined by Weiss and Enzinger in 1982 [1] as a type of hemangioendothelioma, and it is defined by the National Institute of Medicine [2] as "a tumor of medium-to-large veins composed of plump-to-spindled endothelial cells that bulge into vascular spaces in a tombstone-like fashion” (p. 899). From 2000 through 2004, the National Cancer Institute's Surveillance Epidemiology and End Result database recorded 25 cases of EHE in the liver, 1 case in the lungs, and 8 cases in the bones and joints [3]. During this same period, 59 cases of ERE were recorded for other regions of the body. EHE of the liver and lungs appear most frequently in women during their third decade of life [4,5]. The mortality rate for EHE varies according to the anatomic location and aggressiveness of the disease $[6,7]$.

EHE is a type of hemangioendothelioma that involves two major tissues: epithelium and endothelium, the connective tissue lining the inside and outside of the body, its cavities, and viscera, respectively [8]. Although epithelium and endothelium are similar in function, the histological structures of these tissues differ [9]. EHE tumors are composed of endothelial cells that mimic the appearance of epithelium $[1,10]$. These tumors surround organs and occlude blood flow to themselves and neighboring organs $[11,12,13]$. Other microscopic histological characteristics of EHE include Weibel-Palade bodies, pinocytic vessels, immature vessels, and dendritic cells $[1,14]$. EHE tumors are also vacuolated, possessing large cavities that can imitate other types of cells, which may lead to incorrect diagnosis [15]. Furthermore, EHE tumors can assume a nest-like appearance $[16,17,18]$. Analysis of the cellular architecture of EHE is crucial to accurate diagnosis.

The precise cause of EHE has yet to be elucidated. Many researchers supported the theory that exposure to vinyl chloride and the use of oral contraceptives are risk factors for EHE [19,20]. Genetic data are limited; however, some researchers have proposed various chromosomal abnormalities as contributing factors to the development of EHE [21]. Theurillat [22] discovered a high level of vascular endothelial growth factor (VEGF) in a 59-yearold woman with metastatic EHE. Similarly, Theurillat [22] 
postulated that placental growth factor activated VEGF, possibly contributing to EHE in the foot of a 56-year-old female patient. Marsh [23] theorized that silicone from polyurethane-enclosed breast implants is a cause of EHE of the liver and lungs. Race and ethnicity do not appear to be significant risk factors for EHE [1,6].

The American Cancer Society [24] reported that the formation of cancerous tumors and mutation of cells into cancerous cells might be prevented by controllable factors such as diet, exercise, and other individual life choices. The ACS estimated that obesity accounted for approximately 186,550 cancers fatalities in 2007. The indirect economic cost of cancer incidence within the United States (U.S.) exceeded \$110 billion in 2006 [24]. Although no direct link has been found between any type of EHE and obesity or alcohol, researchers have suggested that obesity and alcohol are contributive to various forms of cancer [25,26,27,28]. For example, Wong [28] found cancer to be a modifiable risk factor for breast cancer. Similarly, Adams [25,26] found that obesity and excessive alcohol consumption are linked to breast cancer.

Consequently, this study was undertaken to investigate excessive alcohol consumption and obesity as potential risk factors for EHE. Toward this aim, two research questions were addressed. Firstly, a potential relationship between the regional obesity rate and prevalence rate of EHE of the liver, lungs, and bones in the U.S. was examined. Secondly, a potential relationship between the regional excessive alcohol consumption rate and prevalence rate of EHE of the liver, lungs, and bones in the U.S. was examined.

\section{Materials and Methods}

\subsection{Research Design and Data Sources}

This study used an ecological research design to investigate correlations among obesity, excessive alcohol consumption, and EHE at an aggregate level. The nine tenets of the Bradford Hill criteria of epidemiological causation (power of association, regularity, specificity, temporality, biological gradient (i.e., dose-response), plausibility, rationality, experiment, and analogy) served as the conceptual framework of this study. Obesity is defined by various organizations and in this study as a body mass index of 30 or more [29,30]. Excessive alcohol consumption was defined as more than one standard drink per day for women and more than two standard drinks per day for men [31]. Similarly as other ecological studies [32], this current research analyzed secondary data to address the research questions. Three major sources of data were used in the analysis: the International Hemangioendothelioma Epithelioid and Related Vascular Disorders (H.E.A.R.D.) registry database, the Behavioral Risk Factor Surveillance System (BRFSS) from the Centers for Disease Control and Prevention, and population estimates from the U.S. Census Bureau. In accordance with the divisions of the Environmental Protection Agency, the U.S. was divided into 10 regions (See Table 1). No study has indicated higher EHE prevalence in any single region. The sample size of this study $(N=10)$ is representative of the collective population within all 50 states.
Table 1. Ten Geographical Study Regions

\begin{tabular}{|c|c|}
\hline Region I & Region VI \\
\hline $\begin{array}{c}\text { Connecticut } \\
\text { Maine } \\
\text { Massachusetts } \\
\text { New Hampshire } \\
\text { Rhode Island } \\
\text { Vermont }\end{array}$ & $\begin{array}{c}\text { Arkansas } \\
\text { Louisiana } \\
\text { New Mexico } \\
\text { Oklahoma } \\
\text { Texas }\end{array}$ \\
\hline Region II & Region VII \\
\hline $\begin{array}{c}\text { New Jersey } \\
\text { New York } \\
\text { Puerto Rico } \\
\text { U.S. Virgin Islands } \\
\end{array}$ & $\begin{array}{c}\text { Iowa } \\
\text { Kansas } \\
\text { Missouri } \\
\text { Nebraska } \\
\end{array}$ \\
\hline Region III & Region VIII \\
\hline $\begin{array}{c}\text { Delaware } \\
\text { District of Columbia } \\
\text { Maryland } \\
\text { Pennsylvania } \\
\text { Virginia } \\
\text { West Virginia } \\
\end{array}$ & $\begin{array}{c}\text { Colorado } \\
\text { Montana } \\
\text { North Dakota } \\
\text { South Dakota } \\
\text { Utah } \\
\text { Wyoming } \\
\end{array}$ \\
\hline Region IV & Region IX \\
\hline $\begin{array}{c}\text { Alabama } \\
\text { Florida } \\
\text { Georgia } \\
\text { Kentucky } \\
\text { Michigan } \\
\text { Mississippi } \\
\text { North Carolina } \\
\text { South Carolina } \\
\text { Tennessee } \\
\end{array}$ & $\begin{array}{c}\text { Arizona } \\
\text { California } \\
\text { Hawaii } \\
\text { Nevada } \\
\text { Pacific Islands }\end{array}$ \\
\hline Region V & Region X \\
\hline $\begin{array}{c}\text { Illinois } \\
\text { Indiana } \\
\text { Michigan } \\
\text { Minnesota } \\
\text { Ohio } \\
\text { Wisconsin }\end{array}$ & $\begin{array}{c}\text { Alaska } \\
\text { Idaho } \\
\text { Oregon } \\
\text { Washington }\end{array}$ \\
\hline
\end{tabular}

\subsection{Data Collection and Analysis}

Upon approval from the Walden Institutional Review Board, data were compiled from the three described sources. Data were collected from December 2008 to October 2009. Documented cases of EHE of the liver, lungs, and bones in each of the 10 U.S. regions were first collected from the H.E.A.R.D. registry. The population estimates of each state were subsequently calculated via data obtained from the U.S. Census Bureau. Prevalence rates of EHE of the liver, lungs, and bones were also calculated for each of the 10 U.S. regions based on the number of cases and population estimates. The crude rate was converted into an age-adjusted rate. Lastly, rates of obesity and excessive alcohol consumption were collected from the BRFSS database and complied for each of the 10 U.S. regions. These crude rates were also converted into age-adjusted rates.

To address the potential relationship between obesity and EHE of the liver, lungs, and bones, a correlation analysis was conducted using the age-adjusted obesity rate and prevalence rate of EHE of the liver, lungs, and bones for each of the 10 U.S. regions. Given the small sample size $(N=10)$, the nonparametric statistical method of correlation analysis (Kendall's tau-b) was applied. The significance level was defined at $p=0.05$.

To address the potential relationship between alcohol consumption and EHE of the liver, lungs, and bones, a non-parametric correlation analysis, using Kendall's tau-b, was conducted using the age-adjusted rates of excessive alcohol consumption rate and the prevalence rate of EHE of the liver, lungs, and bones for each of the 10 U.S. regions. The significance level was defined at $p=0.05$. 
A follow-up multivariate analysis was conducted to control for external factors that may be associated with EHE of the liver, lungs, and bones. The factors included in the follow-up analysis were physical inactivity, cigarette smoking, income, education level, gender, and race. The crude physical inactivity rate and tobacco use rate were first converted into age-adjusted rates. A multiple regression analysis was then conducted on these rates, using the rate of EHE prevalence as the dependent variable. The age-adjusted rates of obesity and excessive alcohol consumption served as independent variables. If the coefficient related to obesity or excessive alcohol consumption was found to be significant at the 0.05 level, the variable was considered a risk factor for EHE.

\section{Results}

\subsection{Regional Demographic Profile}

Table 2 shows the median income, educational level, and gender (\% of males) composition by region. Regions 4 and 6 had the lowest median income, and in both of these regions, the median education level was a high school diploma or equivalent. Region 2 also had a median education level of high school diploma or equivalent but had a higher median income. Regions 7, 8, and 10 shared many characteristics, although regions 8 and 9 had slightly larger male populations. Additionally, regions 1, 2, and 3 shared similar income levels among their populations, but region 1 had a higher male population.

Table 2. Median Income and Education Levels by Region, United States, 2006

\begin{tabular}{|c|c|c|c|}
\hline Region & $\begin{array}{l}\text { Median } \\
\text { income }\end{array}$ & Median educational level & $\begin{array}{l}\% \text { of } \\
\text { Males }\end{array}$ \\
\hline 1 & $\begin{array}{c}\$ 50,000- \\
59,999\end{array}$ & Some college, no degree & 56.7 \\
\hline 2 & $\begin{array}{c}\$ 50,000- \\
59,999\end{array}$ & $\begin{array}{l}\text { High school graduate (includes } \\
\text { equivalency) }\end{array}$ & 48.4 \\
\hline 3 & $\begin{array}{c}\$ 50,000- \\
59,999\end{array}$ & Some college, no degree & 48.6 \\
\hline 4 & $\begin{array}{c}\$ 35,000- \\
39,999\end{array}$ & $\begin{array}{l}\text { High school graduate (includes } \\
\text { equivalency) }\end{array}$ & 48.9 \\
\hline 5 & $\begin{array}{c}\$ 45,000- \\
49,999\end{array}$ & Some college, no degree & 49.1 \\
\hline 6 & $\begin{array}{c}\$ 35,000- \\
39,999\end{array}$ & $\begin{array}{c}\text { High school graduate (includes } \\
\text { equivalency) }\end{array}$ & 49.4 \\
\hline 7 & $\begin{array}{c}\$ 40,000- \\
44,999\end{array}$ & Some college, no degree & 49.1 \\
\hline 8 & $\begin{array}{c}\$ 40,000- \\
44,999\end{array}$ & Some college, no degree & 50.2 \\
\hline 9 & $\begin{array}{c}\$ 45,000- \\
49,999\end{array}$ & Some college, no degree & 50.0 \\
\hline 10 & $\begin{array}{c}\$ 45,000- \\
49,999 \\
\end{array}$ & Some college, no degree & 49.8 \\
\hline
\end{tabular}

\subsection{The Relationship between Regional Obesity and EHE of the Liver, Lungs, and Bones}

Figure 1 shows the age-adjusted regional obesity rate (per 1000) and prevalence rate (per 1,000,000) of EHE of the liver, lungs, and bones that were assessed using Kendall's tau-b. The results from the analysis revealed a positive relationship between the regional obesity rate and prevalence rate of EHE of the liver, lungs and bones in the U.S. $(\tau=0.467, p$ [one-tailed] $=0.03)$.

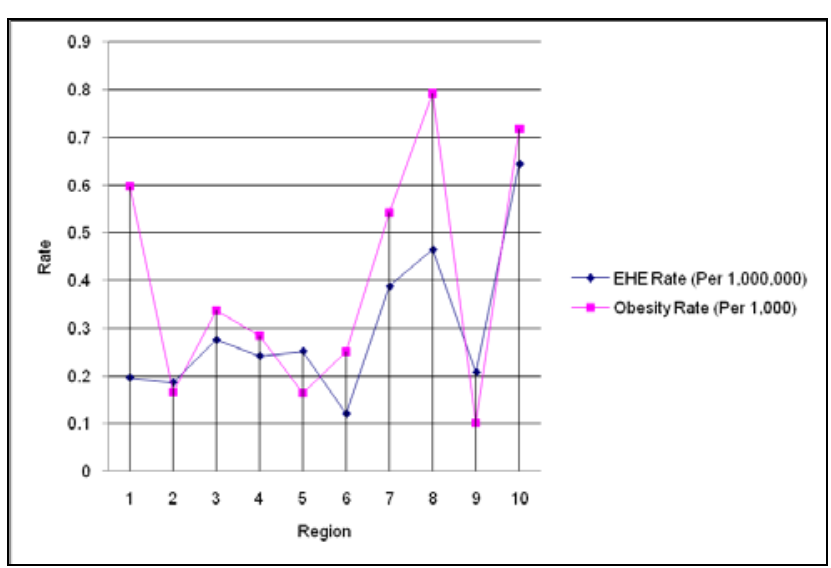

Figure 1. EHE and Obesity Rates by Region, United States, 2006

Table 3. Multiple Regression on Regional EHE Prevalence Rate $(\mathbf{N}=10)$

\begin{tabular}{ccc}
\hline Variables & Model $1 \beta$ & Model $2 \beta$ \\
\hline Constant & $0.16^{* * *}$ & 0.16 \\
Obesity & $0.02^{* * *}$ & 0.02 \\
Physical inactivity & $-0.01^{* *}$ & -0.01 \\
Cigarette smoking & -0.01 & -0.01 \\
Median income & & 0.01 \\
Median educational level & & 0.00 \\
Gender (\% of male) & -0.00 \\
Race (age-adjusted population \% of White) & & 0.02 \\
$R^{2}$ & 0.98 & 0.99 \\
\hline$* * p<0.01 ; * * * p<0.001$ & &
\end{tabular}

Given the described results, a follow-up multiple regression analysis was conducted using Statistical Analysis System (SAS) software to determine whether the rates of regional obesity and prevalence of EHE of the liver, lungs, and bones remained significantly associated after controlling for the potential confounding factors of physical inactivity, cigarette smoking, income, education level, gender, and race. Table 3 shows the results of the regression analysis. Model 1 of Table 3 shows the results of the multiple regression model of the regional obesity rate and prevalence rate of EHE after controlling for physical inactivity and cigarette smoking, and the findings indicate that the regional obesity rate remained significantly associated with the prevalence rate of EHE of the liver, lungs, and bones, after controlling for these variables. Model 2 of Table 3 presents the results of the multiple regression model of regional obesity rate on prevalence rate of EHE after controlling for physical inactivity, cigarette smoking, and other major sociodemographic characteristics of the respective region (i.e., income, educational level, gender, and race), and the data indicate that regional obesity was no longer significantly associated with the prevalence rate of EHE of the liver, lungs, and bones after controlling for these potentially confounding factors. It should be noted that with the small sample size $(N=10)$, Model 2, which had seven independent variables, was nearly saturated. Consequently, an analysis was conducted at the state level to increase the data points, and the results indicated that income was the only marginally significant variable; other variables were not significant (data not shown).

\subsection{The Relationship between Alcohol Consumption and EHE of the Liver, Lungs, and Bones}


The relationship between the regional excessive alcohol consumption rate and prevalence rate of EHE of the liver, lungs, and bones was assessed using Kendall's tau-b (Figure 2). A positive relationship between the regional excessive alcohol consumption rate and prevalence rate of EHE of the liver, lungs, and bones in the U.S. was observed $(\tau=0.422, p$ [one-tailed] $=0.04)$.

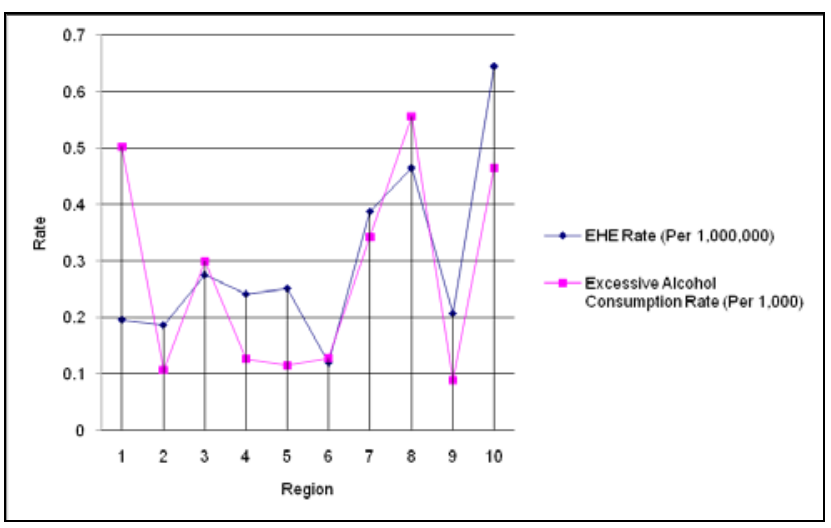

Figure 2. Age-adjusted Regional Excessive Alcohol Consumption Rate by Region United States, 2006

Table 4. Multiple Regression on Regional EHE Prevalence Rate $(\mathrm{N}=10)$

\begin{tabular}{ccc}
\hline Variables & Model 1 $\beta$ & Model $2 \beta$ \\
\hline Constant & 0.16 & 3.23 \\
Excessive alcohol consumption & 0.00 & -0.02 \\
Physical inactivity & -0.01 & -0.01 \\
Cigarette smoking & 0.02 & 0.06 \\
Median income & & 0.08 \\
Median educational level & & 0.16 \\
Gender (\% of male) & & -0.06 \\
Race (age-adjusted population \% of White) & 0.85 \\
$R^{2}$ & 0.74 & 0.95 \\
\hline
\end{tabular}

Given these findings, a follow-up multiple regression analysis was conducted to determine if the rates of excessive alcohol consumption and prevalence of EHE of the liver, lungs, and bones remained significantly associated after controlling for the potentially confounding factors of physical inactivity and cigarette smoking as well as other sociodemographic characteristics of the respective regions. Table 4 presents the regression results. Model 1 of Table 4 shows the results of the multiple regression model of the regional excessive alcohol consumption rate and prevalence rate of EHE after controlling for physical inactivity and cigarette smoking, and the results indicate that the regional excessive alcohol consumption rate is not significantly associated with the prevalence rate of EHE of the liver, lungs, and bones after controlling for these potentially confounding factors. Model 2 of Table 4 shows the results of the multiple regression model of the regional excessive alcohol consumption rate and prevalence rate of EHE after controlling for physical inactivity, cigarette smoking, and other major sociodemographic characteristics of the region. After controlling for these factors, the regional excessive alcohol consumption rate was not significantly associated with the prevalence rate of EHE of the liver, lungs, and bones.

\section{Discussion}

The findings of this study suggest that although excessive alcohol consumption is significantly associated with the prevalence rate of EHE of the liver, lungs, and bones in a bivariate context, it was not a predictor of EHE in a multivariate context. However, it is premature to exclude alcohol consumption as a potential contributing factor to EHE of the liver, lungs, and bones because the related data collected in this study were obtained from self-report surveys. It is therefore possible that the respondents underreported their alcohol consumption due to social pressures [33]. Additionally, this research assessed the association between alcohol consumption and EHE of the liver, lungs, and bones based on the definition of "excessive alcohol consumption" by the DHHS and USDA. Although many health problems have been associated with excessive alcohol consumption [29], there is no consensus surrounding what constitutes excessive consumption. Heredity, body size, and pattern of consumption are all important factors that should be considered regarding alcohol consumption. Due to the rarity of EHE of the liver, lungs, and bones, a universal definition of excessive alcohol consumption (mostly based on quantity) may not capture the potential effects of alcohol consumption on EHE. Lastly, this study applied an ecological research design. For retrospective observational studies, findings at the group level are generalized to the individual level. Moreover, ecological studies utilize secondary data, and they are used when individual level data is nonexistent or difficult to obtain [34].

Given the strong association between the rates of regional obesity and prevalence of EHE of the liver, lungs, and bones, it is reasonable to consider obesity a potential contributing factor to EHE of the liver, lungs, and bones from the standpoint of an ecological study. Public health officials have widely touted obesity and alcohol consumption as risk factors for a wide range of diseases. EHE has no confirmed risk factors; however, many investigators have postulated its causal factors.

The theoretical construct of this study is the Bradford Hill criteria. The results from this study meet four of Hill's nine criteria: strength of association, biological gradient, plausibility, and coherence. This study revealed obesity as a risk factor for EHE. Hill stated that strength of association is determined by clear evidence that the cause of disease occurs before the ailment and is directly associated with the ailment [33]. The biological gradient, as Hill described it, is dose-response. For example, the likelihood of developing a disease associated with cigarette smoking increases with increasing smoking frequency. Biological gradient can be difficult to prove, as researchers have found that small amounts of a "bad thing” can have positive effects [35]. In the current study, biological gradient can be argued for obesity due to the existence of a well-established measure for what is considered obese. Hill described plausibility as a rational basis for a conclusion and coherence as consistency with other knowledge [32]. Obesity and alcohol consumption pose a risk to an individual's health status. Obesity may contribute to EHE because obesity causes stress on the body, requiring the organs to work harder. Excess adipose tissue can surround organs, potentially resulting in changes in their structure and function [36].

The findings related to excessive alcohol consumption suggest that although the rate of excessive alcohol consumption was significantly associated with the 
prevalence of EHE of the liver, lungs, and bones in a bivariate context, it was not a predictor of the prevalence rate of EHE of the liver, lungs, and bones in a multivariate context. Given these findings, the Bradford Hill criteria cannot be applied. However, it is important to remember Hill's (2005) advice when applying his theory: "None of my nine viewpoints can be indisputable evidence for or against the cause-and-effect hypothesis and none can be required as a sine qua non" [34]. Furthermore, it is important to remember that excessive alcohol consumption was self-reported in this study and hence may not have been reliably measured.

There are four major limitations to this study. First, similarly as ecological studies [32], this study suffered from the potential limitation of ecological fallacy. That is, the retrospective observational data compiled at the group level may not be generalizable to the individual level. Second, this study was also limited by the quality of data used in the analysis. This study used secondary data that were volunteered or self-reported. Consequently, it is possible that respondents provided answers they considered socially acceptable [33]. The generalizability of the results of this study may be limited due to sample bias in the secondary data collected. The nature of this bias may be associated with variables that were addressed by a BRFSS telephone survey. Telephone surveys exclude households without telephones; however, it is important to note that the questions taken from the BRFSS and used in this survey have been reported to be highly reliable [37]. The H.E.A.R.D. registry possesses more cases than the National Institute of Health, but the data available in the registry are by no means comprehensive or exhaustive. The registry is updated and maintained by its members [38]. Given the rarity of EHE cases, the prevalence rate of EHE will be biased without a comprehensive and exhaustive case registry The registry likely contains errors, which would bias the prevalence rate of EHE. The third limitation of this study is the small sample size. The fourth limitation is diagnostic error.

Although there has been much research conducted on various cancers, rare forms of cancer such as EHE can remain a mystery for years. Many studies have supported the fact that obesity and alcohol consumption contribute to multiple types of cancer. Moreover, obesity and alcohol consumption contribute to other types of health problems. This study has shown a correlation between obesity and EHE and a possible association between EHE and excessive alcohol consumption. Further studies using different methodologies and larger cohorts are needed to affirm these results.

\section{References}

[1] Maklouf H, Ishak K, Goodman Z. Epithelioid hemangioendothelioma of the liver: A clinicopathologic study of 137 cases. Cancer 1999; 85: 562-582.

[2] National Library of Medicine Medical subject headings (MeSH) 2008. Hemangioendothelioma. Retrieved from http://www.nlm.nih.gov/cgi/mesh/2008/MB_cgi?mode=\&term=H emangioendothelioma,+Epithelioid\&field $=$ entry.

[3] National Cancer Institute Surveillance Epidemiology and End Results 2008. Retrieved from http://seer.cancer.gov.

[4] Chen TM, Donington J, Mak G, Berry GJ, Ruoss SJ, Rosen GD, et al. Recurrence of pulmonary intravascular bronchoalveolar tumor with mediastinal metastasis 20 years later. Respir Med 2006; 100 (2): 367-370.

[5] Díaz R, Segura A, Calderero V, Cervera I, Aparicio J, Jordá MV, et al. Central nervous system metastases of a pulmonary epithelioid haemangioendothelioma. Eur Respir J 2004; 23 (3): 483-486.

[6] Dail DH, Liebow AA, Gmelich JT, Friedman PJ, Miyai K, Myer $\mathrm{W}$, et al. Intravascular, bronchiolar, and alveolar tumor of the lung (IVBAT): An analysis of twenty cases of a peculiar sclerosing endothelial tumor. Cancer 1983; 51: 452-464.

[7] Posligua L, Anatelli F, Dehner LP, Pfeifer JD. Primary peritoneal epithelioid hemangioendothelioma. Int J Surg Pathol 2006; 14 (3): 257-267.

[8] Sormunen C. Terminology for allied health professionals. Clifton Park: Thomson Delmar Learning; 2003.

[9] Pusztaszeri M, Bosman F, Seelentag W. Immunohistochemical expression of endothelial markers. J Histochem Cytochem 2006; 54: 385-395.

[10] Miller WJ, Dodd GD III, Federle MP, Baron RL. Epithelioid hemangioendothelioma of the liver: imaging findings with pathologic correlation. AJR Am J Roentgenol 1992; 159: 53-7.

[11] Mallory FB. The results of the application of special histological methods to the study of tumors. J Exp Med 1908; 10 (5): 575-593.

[12] Mascarenhas RC, Sanghvi AN, Friedlander L, et al. Thalidomide inhibits the growth and progression of hepatic epithelioid hemangioendothelioma. Oncology. 2004; 67: 471-5.

[13] Pokharna, Rupesh K., Pramod Kumar Garg, Siddhartha Datta Gupta, Usha Dutta, and Rakesh K. Tandon. "Primary epithelioid haemangioendothelioma of the liver: case report and review of the literature." Journal of clinical pathology 50, no. 12 (1997): 10291031.

[14] Earnest IV, Frank, and C. Daniel Johnson. "Case 96: Hepatic Epithelioid Hemangioendothelioma 1." Radiology 240, no. 1 (2006): 295-298.

[15] Hristov EN, Krishnamurthy S, Ro JY, Ayala AG. Pulmonary epithelioid hemangioendothelioma with prominent signet ring cell features mimicking metastatic adenocarcinoma. Ann Diagn Pathol 2003; 7 (3); 160.

[16] Kabukcuoglu, Fevziye, Yavuz Kabukcuoglu, Ayten Livaoglu, Aysim Ozagari, Raffi Armagan, and Unal Kuzgun. "Epithelioid hemangioendothelioma of bone." Acta orthopaedica et traumatologica turcica 40, no. 4 (2004): 324-328.

[17] Pins, M. R., H. J. Mankin, R. J. Xavier, D. I. Rosenthal, G. R. Dickersin, and A. E. Rosenberg. "Malignant epithelioid hemangioendothelioma of the tibia associated with a bone infarct in a patient who had Gaucher disease." JOURNAL OF BONE AND JOINT SURGERY-AMERICAN VOLUME-77 (1995): 777-777.

[18] Yoshida, Haruhiko, Mari Watanabe, Takeshi Minamizaki, and Nobuyuki Takasu. "Multicentric epithelioid hemangioendothelioma of the bone: histologic and radiographic features." Yonago Acta Med 43 (2000): 87-92.

[19] Hermann G, Klein M, Abdelwahad I, Springfield D. (2002). Clear cell sarcoma (malignant melanoma of soft parts): case report and review of the literature. Can Assoc Radiol J 2002; 53 (4): 237-241.

[20] Mucha K. Patient with liver epithelioid hemangioendothelioma treated by transplantation: 3 years' observation. Transpl $P$ 2006; 38 (1): 231-233.

[21] Tsarouha, Haroula, Anastasios I. Kyriazoglou, Franclim R. Ribeiro, Manuel R. Teixeira, Niki Agnantis, and Nikos Pandis. "Chromosome analysis and molecular cytogenetic investigations of an epithelioid hemangioendothelioma." Cancer genetics and cytogenetics 169, no. 2 (2006): 164-168.

[22] Theurillat J-P, Vavricka S, Went P, Weishaupt D, Perren A, Leonard-Meier C, et al. Morphologic changes and altered gene expression in an epithelioid hemangioendothelioma during a tenyear course of disease. Pathol Res Pract 2003; 199: 165-170.

[23] Marsh D. Breast implants as a possible etiology of epithelioid hemangioendothelioma and successful therapy with Interferon- $\alpha 2$. The Breast Journal 2005; 11 (4): 257-261.

[24] American Cancer Society 2007. Cancer facts and figures, 2007. Retrieved

from http://www.cancer.org/downloads/STT/CAFF2007PWSecured.pdf.

[25] Adams SL. Heavy alcohol consumption increased risk for prostate cancer. Hem/Onc Today, 2009; 10 (16): 25.

[26] Adams SL. Obesity, smoking, alcohol consumption related to risk for contralateral breast cancer. Hem/Onc Today, 2009; 10 (19): 30. 
[27] Harris J. Alcohol consumption increased risk for breast cancer recurrence by 34\%. Hem/Onc Today 2010; 11 (1): 14.

[28] Wong, A. W. (2010). Alcohol Consumption and Breast Cancer. Cur Med Lit: Breast Canc 2010; 22 (2): 41-47.

[29] Centers for Disease Control 2008. Quick stats general information on alcohol use and health. Retrieved from http://www.cdc.gov/alcohol/quickstats/general_info.htm.

[30] World Health Organization 2006. Cancer. Retrieved from http://www.who.int/mediacentre/factsheets/fs297/en/.

[31] Centers for Disease Control 2008. Alcohol and public health. Retrieved from http://www.cdc.gov/alcohol/index.htm.

[32] Höfler, M. (2005). The Bradford Hill considerations on causality: a counterfactual perspective. Emerg Themes Epidemiol 2005;2:11.

[33] Stockwell T, Donath S, Cooper-Stanbury M, Chikritzhs T, Catalano P, Mateo C. (2004). Under-reporting of alcohol consumption in household surveys: a comparison of quantity- frequency, graduated-frequency and recent recall. Addiction 2004; 99 (8): 1024-1033.

[34] Haneuse S, Wakefield J. (2007). Hierarchical models for combining ecological and case-control data. Biometrics 2007; 63 (1): $128-136$.

[35] Dumitrescu, R. G., and I. Cotarla. "Understanding breast cancer risk-where do we stand in 2005?.” Journal of cellular and molecular medicine 9, no. 1 (2005): 208-221.

[36] Frisbee J. (2007). Vascular dysfunction in obesity and insulin resistance. Microcirculation 2007; 14 (4-5): 269-271.

[37] Mokdad, Ali H., Wayne H. Giles, Barbara A. Bowman, George A. Mensah, Earl S. Ford, Suzanne M. Smith, and James S. Marks. "Changes in health behaviors among older Americans, 1990 to 2000.” Public Health Reports 119, no. 3 (2004): 356.

[38] H.E.A.R.D Support Group. The International H.E.A.R.D. Registry. Retrieved from http://www.H.E.A.R.D.support.org/registry.html 